Research Article

\title{
Research on Bearing Characteristics of Open-Ended Pipe Piles under Static Load
}

\author{
Haibao Feng $\mathbb{D}^{1,2}$ Xingke Dai $\mathbb{D}^{3},{ }^{3}$ Shuiyue Chen $\mathbb{D}^{3},{ }^{3}$ and Jianwei Chen $\mathbb{D}^{3}$ \\ ${ }^{1}$ State Key Laboratory of Hydraulic Engineering Simulation and Safety, Tianjin University, Tianjin 300072, China \\ ${ }^{2}$ The Second Engineering Co., Ltd., of CCCC First Harbor Engineering Co., Ltd., Qingdao 266071, China \\ ${ }^{3}$ Institute of Civil Engineering, Qingdao University of Technology, Qingdao 266033, China \\ Correspondence should be addressed to Haibao Feng; xxhfhb@ccccyhj.com
}

Received 24 January 2021; Revised 21 March 2021; Accepted 2 April 2021; Published 14 April 2021

Academic Editor: Yunteng Wang

Copyright $\odot 2021$ Haibao Feng et al. This is an open access article distributed under the Creative Commons Attribution License, which permits unrestricted use, distribution, and reproduction in any medium, provided the original work is properly cited.

The accurate estimate of the ultimate bearing capacity of a single pile in the vertical direction is an important issue in the design of the pile foundation. This paper presents a static test on a single-pile model. The test was performed through a large-scale model casing test equipment that is independently developed. Various factors that affect the different test soil samples have been taken into account. In addition, the test has measured the pile's internal stress and displacement through the sensors that were installed on the pile. What is more, a series of studies on the settling character of the single pile, pile lateral friction, changing nature of tip resistance, and its development with settling have been carried out. Finally, this paper analyzes the bearing capacity behavior and load transfer mechanism in the compressive static load test on the single pile in the vertical direction. The test results show that, under the same static load, the lateral friction of a pile in the sand is bigger than that in the silty clay, and with the increasing load at the pile tip, the increment speed of tip resistance in the silty clay is much faster than that in the sand, while pile's bearing capacity in the sand is much bigger than that in the silty clay.

\section{Introduction}

The rapid urbanization has led to huge demands on the infrastructure constructions in city area. Meanwhile, the pile foundation is one of the most common forms of the infrastructure foundations in the constructional engineering. The design concept of the pile foundation with settling control has increasingly been accepted by the academia and engineering community [1]. The most urgent problems in optimizing the settling control for the pile foundation design include the following: how to figure out the load transfer mechanism at the pile-soil interface during the static load process; what is the development nature of tip resistance with pile settling; how to seasonably calculate the pile foundation settling. These issues provide a theoretical foundation for the accurate estimate of the ultimate bearing capacity of a pile. Many scholars explore the working mechanism of a single pile by bringing forward empirical methods [2, 3], elastic theory method [4], load transmitting method [5-7], and numerical method $[8,9]$. These methods study the mechanical property of the static load from a macroscopic perspective; therefore, they have limited application range. Some scholars have used the Mohr-Coulomb criterion to study the fracture state of rock under the ultimate load-bearing state through the comparative analysis of model tests and numerical simulations and have made good progress [10-15]. In addition, according to the principle of layerwise summation method, Hong and Yang in 2008 extended the elastic theory based on Mindlin displacement solution and successfully established a method similar to the single-pile load distribution and settlement calculation under soil hierarchical solution [16]. In 2010, Wang et al. studied the rule of distribution for the lateral and tip resistances under different loads [17], as well as the changing nature of lateral friction with the settling of pile tip and of a pile in sand layer and silty clay with the relative displacement of such sand or silty clay. In the same year, Zhou et al. conducted an indoor single-pile static model test 
through their independently designed visible box model [18], and by taking into account the influencing factors on different pile diameters and soil compactness, their team studied the settlement mode of the single pile, changing nature of lateral, tip resistances, and their development with settling. Their results further revealed the micro- and macromechanisms in the static load process. In 2011, Diao et al. explored the static load test on pile under different loads through on-site test and finite element modeling [19]. In 2012, Hong applied the elastic theory based on Mindlin displacement solution to the establishment of a theoretical simulation method by conducting the single-pile static load test based on pile-loading and achor-pile methods [20]. They also made a contrastive analysis between the two methods. In 2016, Gao et al. conducted and analyzed the PHC pile static test in Qingdao [21], and their study indicates that PHC pile has a great bearing potential in the complex geology of Jiaozhouwan reclamation area. In 2017, Huang and Zhang combined three socketed piles that were taken from a construction project in Qingdao to perform an on-site static load test and have studied the settling nature [22]. In 2020, Huo et al. conducted field tests based on the rock-socketed pile foundation of an engineering quartz sandstone formation and obtained the lateral resistance and end resistance through the conversion of uniaxial compressive strength theory [23]. However, the mechanical property of soil comes from the reaction of all elements in the soil. To the best of the authors' knowledge, only a few studies focus on the mechanical property of soil in the static load process.

Through the indoor test on the large-scale open pile model, this paper studies the settlement mode, bearing capacity, and lateral friction during the static load process of a single pile, as well as the working nature of tip friction, which have revealed the internal mechanism of pile-soil interaction in static load process.

\section{The Indoor Model Test on Single Pile's Static Load}

2.1. The Equipment and Soil Sample Used for Indoor Model Test. This test adopts the large-scale model casing equipment that is independently developed by the Qingdao University of Technology, with its internal dimension of $3000 \mathrm{~mm} \times 3000 \mathrm{~mm} \times 2000 \mathrm{~mm}(L \times W \times H)$, as shown in Figure 1. The dimension of its steel plate installed on its facade is $900 \mathrm{~mm} \times 900 \mathrm{~mm} \times 6 \mathrm{~mm}$ ( $L \times W$ Thickness $)$, as a discharge opening for the convenience of disassembly. Tempered glass is installed at intervals in the middle of the facade as the viewing windows. The equipment is soldered together with steel plate, and its welding lines are sealed with high-strength solid sealant for waterproof. Its drainage adopts stainless steel tubes equipped with ball valves, which are installed at its four corners for the drainage consolidation of soil sample. All of the steel used for the equipment is painted with peacock blue antirust paint, with servo-load

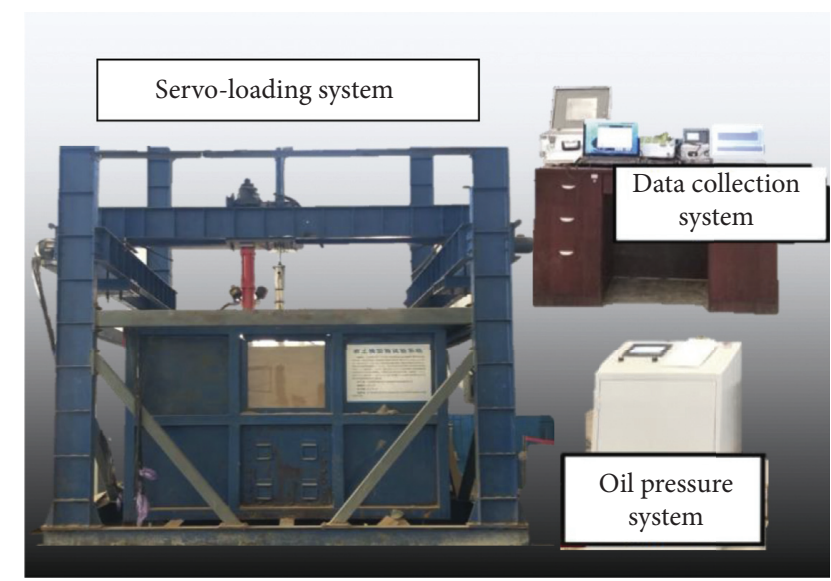

Figure 1: The large-scale model casing test equipment.

system used for loading in static load process, as shown in Figure 1.

The pile model used for the test consists of two aluminum alloy tubes with concentric circles, and their inner and outer tubes are connected to the pile shoe, with Poisson's ratio 0.3 and elasticity modulus $72 \mathrm{GPa}$. The pile model P1 is of $1000 \mathrm{~mm}$ long, $140 \mathrm{~mm}$ in diameter, and $13 \mathrm{~mm}$ in thickness, while the pile model P2 is of $1000 \mathrm{~mm}$ long, $160 \mathrm{~mm}$ in diameter, and $13 \mathrm{~mm}$ in thickness. Except for the diameter, the pile model P1 and P2 are made in the same structure, as shown in Figure 2. The cross-sectional dimensions of P1's outer tube are $140 \mathrm{~mm} \times 134 \mathrm{~mm}$ (outer $\times$ inner diameter) and $3 \mathrm{~mm}$ in thickness, while the cross-sectional dimensions of its inner tube are $120 \mathrm{~mm} \times 114 \mathrm{~mm}$ (outer $\times$ inner diameter) and $3 \mathrm{~mm}$ in thickness. The cross-sectional dimension of P2's outer tube is $160 \mathrm{~mm} \times 154 \mathrm{~mm}$ (outer $\times$ inner diameter) and $3 \mathrm{~mm}$ in thickness, while the cross-sectional dimension of its inner tube is $140 \mathrm{~mm} \times 134 \mathrm{~mm}$ (outer $\times$ inner diameter) and $3 \mathrm{~mm}$ in thickness.

On the outer wall of the outer tube, a groove is opened for fiber bragg grating (FBG) microsensor to be stuck in and sealed with epoxy resin glue, while the sensor of inner tube is also installed onto its outer wall and placed into the enclosed annular space to protect it from environmental disturbance (see Figure 3 for both tubes). Both the inner and outer tubes for FBG microsensor installment are in a symmetrical layout on both sides. Starting from the pile tip, the height of outer tube should be, respectively, $20 \mathrm{~mm}$, $200 \mathrm{~mm}, 380 \mathrm{~mm}, 560 \mathrm{~mm}, 740 \mathrm{~mm}$, and $920 \mathrm{~mm}$, and on each side of the outer tube, six sensors should be installed, totaling 12. The height of inner tube should be, respectively, $20 \mathrm{~mm}, 110 \mathrm{~mm}, 200 \mathrm{~mm}, 290 \mathrm{~mm}, 380 \mathrm{~mm}, 560 \mathrm{~mm}$, and $740 \mathrm{~mm}$, and on each side of the inner tube, seven sensors should be installed, totaling 14 sensors. FBG microsensor measures the axial force of pile shaft through detecting the pile strain change in order to get the shaft friction. The stress obtained by the sensor at the bottom of outer tube is approximately equal to tip resistance, and the displacement 


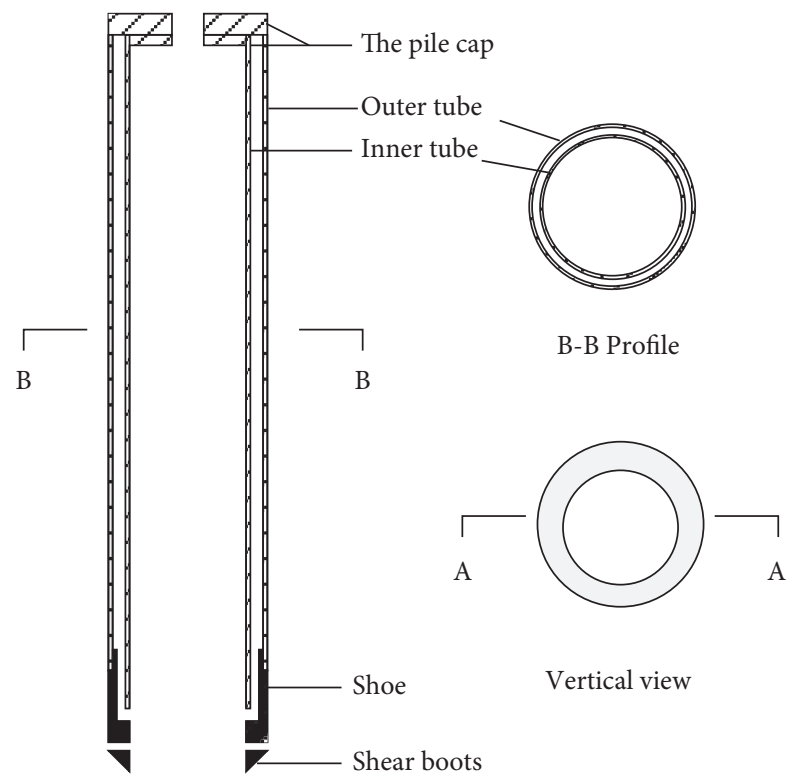

A-A Profile

Figure 2: The structure of double-walled pile.

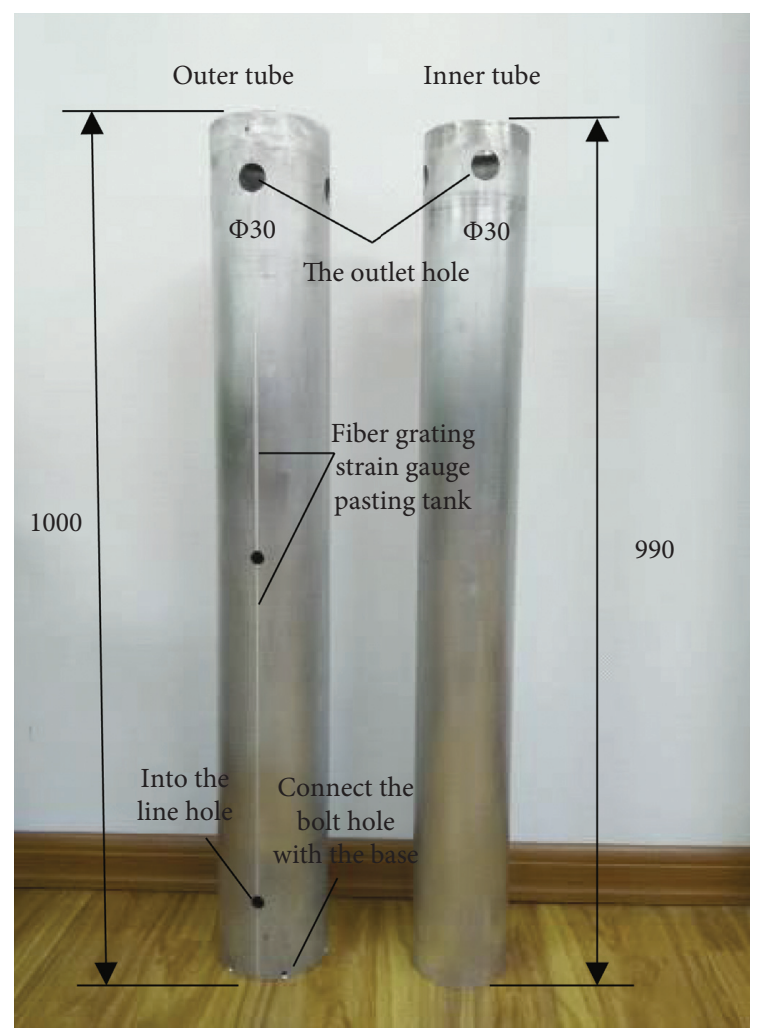

Figure 3: The inner and outer tubes of double-walled open-ended pile.

and accumulated settlement at the pile tip are measured through the displacement sensor of the servo-loading system.

Two soil samples are used for this test: one is the sea sand, and the other is the silty clay taken in a Qingdao area.
The sea sand used is dried out to reduce the influence from other factors, and the relative density of the sand is $G_{S}=2.65$; maximum void ratio is $e_{\max }=0.52$; minimum void ratio is $e_{\min }=0.30$; relative compactness is $D_{r}=0.73$; median size is $d_{50}=0.72 \mathrm{~mm}$; particle size range $(\mathrm{mm})$ is $0-15$; internal friction angle is $\phi=42.8^{\circ}$; dry density is $\rho_{d}=1.95 \mathrm{~kg} / \mathrm{mm}^{3}$. The grain composition obtained through sieving method is shown in Figure 4.

As for the silty clay, its optimum moisture content is $w=23 \%$; maximum dry density is $\rho_{d}=1.69 \mathrm{~kg} / \mathrm{mm}^{3}$; liquid limit is $w_{l}=31.6 \%$; plastic limit is $w_{p}=13.8 \%$; plastic index is $I_{p}=17.9 \%$; internal friction angle is $\varphi=30^{\circ}$; cohesive force is $c=27 \mathrm{kPa}$; compressibility coefficient is $\partial_{v 1-2}=0.32 \mathrm{MPa}$; compression modulus is $E_{S 1-2}=5.5 \mathrm{MPa}$; Poisson's ratio is 0.3 . Soil is filled into the foundation by layer and then compacted manually or mechanically. After the preparation is finished, slowly add water into the soil until complete saturation and then wait for $20 \mathrm{~d}$ to ensure that the moisture in the soil is evenly distributed.

2.2. Soil Preparation. According to inner dimensions of casing model $3000 \mathrm{~mm} \times 3000 \mathrm{~mm} \times 2000 \mathrm{~mm}$ (length $\times$ width $\times$ height), the height of soil sample is $1800 \mathrm{~mm}$, and the sample is filled into the casing model in nine times, and large scraper is used to fill in the soil at $200 \mathrm{~mm}$ each time, and each layer of the soil sample is tamped down both manually (two times) and mechanically (one time). Each layer of soil is given at least $12 \mathrm{~h}$ for its self-compactness relying on gravity, so as to ensure the homogeneity of test sample. In each layer of soil, eight cutting rings are placed each at $300 \mathrm{~mm}$ from the edge to the four faces of the casing model. After the test, take out all cutting rings from each layer to measure the soil compactness and work out the average compactness.

\subsection{Test Procedures}

\subsubsection{Test Preparation.}

(1) Fill the soil sample into the casing model with layers at a height of $200 \mathrm{~mm}$ for each layer, manually (two times) and mechanically (one time), until the soil at each layer is tamped to the required height.

(2) Place an open-ended pile into the casing model after determining its sinking position in the casing model, using a leveling rod to adjust the perpendicularity of the pile, so as to ensure its perpendicularity during pile sinking.

(3) Use a hydrocylinder to slowly press the pile to reach the required height. After sinking the pile into the required position, give the sand sample at least $15 \mathrm{~d}$ and the saturated foundation soil at least $28 \mathrm{~d}$ before starting the test.

2.3.2. Loading and Measurement. The servo-loading system and the casing model counterforce device are adopted as the loading devices for this test. The pile is applied with net load 


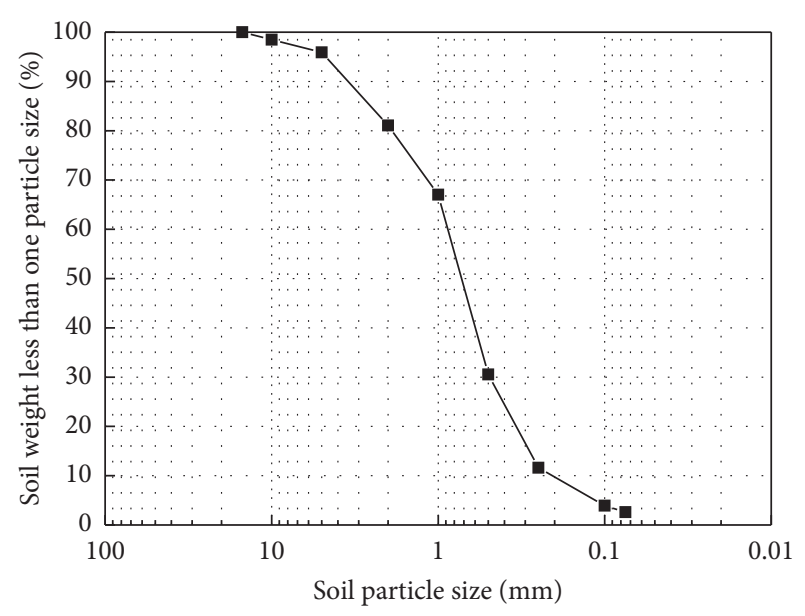

FIgURE 4: The grain composition of sand sample.

by the grading of servo-loading system to reach the ultimate load. The loading in the test is in accordance with the slow maintenance loading method as specified in The Technical Code for Building Pile Foundation (JGJ94-94) [24].

During the static test, net load is applied by the servoloading system through the loading device to reach the ultimate load. In the sand, the load of pile model in the first level is $8 \mathrm{kN}$; in the second level, it is $16 \mathrm{kN}$; in the third level, it is $24 \mathrm{kN}$; in the fourth level, it is $32 \mathrm{kN}$; in the fifth level, it is $40 \mathrm{kN}$ or damaged. In silty clay, the load of pile model in the first level is $1 \mathrm{kN}$; in the second level, it is $2 \mathrm{kN}$; in the third level, it is $3 \mathrm{kN}$; in the fourth level, it is $4 \mathrm{kN}$; in the fifth level, it is $5 \mathrm{kN}$; in the sixth level, it is $6 \mathrm{kN}$; in the seventh level, it is $7 \mathrm{kN}$; in the eighth level, it is $8 \mathrm{kN}$; in the ninth level, it is $9 \mathrm{kN}$ or damaged. Loading should be stopped if, at a certain level, the settling volume of the pile model under the load effect is five times as much as the settling volume of the previous level, or there is no obvious increase in the load of pile foundation.

2.3.3. The Measurement on Stress and Deformation. Before loading at each level, record the data collected by each pile sensor and measure the displacement at the pile tip. Load for $30 \mathrm{~min}$ to repeat the aforementioned operation, and then measure the displacement at the pile tip after each 15 min of loading. The specific test plan is shown in Table 1.

\section{Test Data Analysis}

3.1. The Axial Force of Pile Shaft. According to the data collected from the sensors, we can obtain the axial force of pile shaft through the following formula:

$$
N_{i}=\frac{R_{i}}{S_{i r}} \times 10^{-3} E A=\varepsilon_{i} E A,
$$

in which $N_{i}$ is the axial force $(\mathrm{kN})$ of $i$ section; $R_{i}$ is the data (nm) collected by the sensor of $i$ section; $S_{i r}$ is the sensitivity coefficient $(\mathrm{Pm} / \mu \varepsilon)$ of the sensor of $i$ section; $E$ is the elasticity modulus $(\mathrm{kPa})$ of pile model; $A$ is the pile sectional area $\left(\mathrm{m}^{2}\right) ; \varepsilon i$ is the strain measured by the sensor of $i$ section.
3.2. Lateral Friction. According to the axial force of each section, pile lateral friction can be obtained through the following formula:

$$
F_{i}=N_{i}-N_{i+1}
$$

According to the lateral friction of soil layer, the unit side friction of such layer can be worked out through the following formula:

$$
f_{i}=\frac{F_{i}}{U l_{i}}
$$

in which $F_{i}$ is the lateral friction $(\mathrm{kN}) ; N_{i}$ is the axial force $(\mathrm{kN})$ of $i$ section; $N_{i}+1$ is the axial force $(\mathrm{kN})$ of $i$ section; $f_{i}$ is the unit side friction $(\mathrm{kPa})$ of $i$ layer; $\mathrm{U}$ is the perimeter $(\mathrm{m})$ of pile section; $l_{i}$ is the distance $(\mathrm{m})$ from $i$ layer section to $i+1$ layer section.

3.3. Tip Resistance. According to the data collected by the sensor at the bottom of pile lateral side, the tip resistance can be worked out through the following formula:

$$
F_{d}=\varepsilon E A,
$$

where $F_{d}$ is the tip resistance; $\mathcal{E}$ is the stress measured by the sensor of the section; $E$ is the elasticity modulus $(\mathrm{kPa})$ of pile model; $A$ is the pile sectional area $\left(\mathrm{m}^{2}\right)$.

\section{Test Results Analysis}

4.1. Pile Working Principle. At the start of the static test, the increasing load will first compress the upper part of the pile, with part of the load passing down and the other part becoming lateral friction. With increasing load, the compressed upper part of the pile will have a relative displacement, while the lateral side will receive an upward side friction. When all of the lateral frictions have reached the limit and the load is still increasing, the pile tip will bear more load; the tip settlement will also grow and even reach or surpass the allowable deformation, and the pile will be damaged.

4.2. Pile Test Results. The purposes of this indoor large-scale static test on open-ended pile include the following: (1) studying the basic mode of single-pile settlement in the sand and silty clay; (2) investigating the single-pile bearing capacity, tip resistance, operating characteristic of lateral friction, and development of pile tip displacement under the application of static load.

Figure 5 shows the curves of single pile's tip displacement in different soils for various loading conditions. It can be seen from the figure that the double-walled open-ended pile in the test has an increasing vertical displacement at the pile tip with the application of load at the pile tip increased at the same time. When the vertical displacements are the same at pile tip, the settling volume of $\mathrm{P} 1$ is bigger than that of $\mathrm{P} 2$, and the settling volume of each pile in silty clay is bigger than that in sand. In the test, the ultimate bearing capacity of P1 in silty clay is about $6 \mathrm{kN}$ and that of P2 is about $8 \mathrm{kN}$, while 
TABLe 1: Single-pile static test.

\begin{tabular}{|c|c|c|c|c|c|c|c|}
\hline No. & Type & Shape & $\begin{array}{l}\text { Outer diameter } \\
(\mathrm{mm})\end{array}$ & $\begin{array}{l}\text { Inner diameter } \\
(\mathrm{mm})\end{array}$ & $\begin{array}{l}\text { Length } \\
(\mathrm{mm})\end{array}$ & $\begin{array}{l}\text { The thickness of inner and outer } \\
\text { walls }(\mathrm{mm})\end{array}$ & $\begin{array}{c}\text { Test } \\
\text { sample }\end{array}$ \\
\hline 1 & $\begin{array}{l}\text { Single } \\
\text { pile }\end{array}$ & $\begin{array}{c}\text { Double-walled } \\
\text { open-ended }\end{array}$ & 140 & 114 & 1000 & 3 & Sand \\
\hline 2 & $\begin{array}{l}\text { Single } \\
\text { pile }\end{array}$ & $\begin{array}{c}\text { Double-walled } \\
\text { open-ended }\end{array}$ & 140 & 114 & 1000 & 3 & Silty clay \\
\hline 3 & $\begin{array}{l}\text { Single } \\
\text { pile }\end{array}$ & $\begin{array}{c}\text { Double-walled } \\
\text { open-ended }\end{array}$ & 160 & 134 & 1000 & 3 & Silty clay \\
\hline
\end{tabular}

that of P1 in sand is about $30 \mathrm{kN}$. From the aforementioned, we can see that the bearing capacity of double-walled openended pile in the sand is far bigger than that in the silty clay.

Figure 6 is the curves of single pile's lateral friction in different soils along with load change. As can be seen from the figure, the double-walled open-ended pile in the test has seen its lateral friction increased with the application of load at its tip increased at the same time. Applying the same load, the increment speed of lateral friction in the sand is much faster that in the silty clay. Applying the same load at the pile tip, the lateral friction of pile in the sand is far bigger than that in the silty clay. During the process of static load application, whether in the sand or the clay, the lateral friction of the pile body increases rapidly at the early stage. With the application of the load, the rate of increase of lateral friction of the pile body gradually slows down or even decreases. The main reason is that, at the initial stage of static load application, the pile body mainly resists the deformation and settlement of the pile body through the side friction of the pile body. As the static load increases, the side friction resistance of the pile body is quickly transmitted from top to bottom until the side friction resistance is fully exerted. The static load causes a certain settlement of the pile, the relative displacement between the pile and the soil, and a thin layer of shear band at the pile-soil interface. In the sandy soil, the pile-soil interface shrinks continuously with the static load, which causes the normal stress at the interface to gradually decrease, and the shear stress decreases, which results in softening under reduced pressure. The main mechanism of the stress is that, at the initial stage of static load, the long axis and short axis of the soil particles are arranged in disorder and cross. With the increase of the static load, the settlement of the soil is increasing, the long axis direction of the soil particles is consistent with the shear direction, the soil particles are arranged more orderly, and the space area occupied by the particles is reduced. In addition, with the continuous shearing, the soil particles near the pile-soil interface appear to be very obviously broken. Large soil particles break into small soil particles. The newly broken small particles enter the gap between the large particles, and the soil near the contact surface is further compacted. Therefore, the friction between the pile and the soil is reduced, and the side friction resistance decreases. Due to continuous shear in the clay, a layer of water will gradually form between the pile and the soil, which will play a certain role in lubrication and reduce the interface friction coefficient. Therefore, the side friction resistance of the pile-soil interface will also decrease.

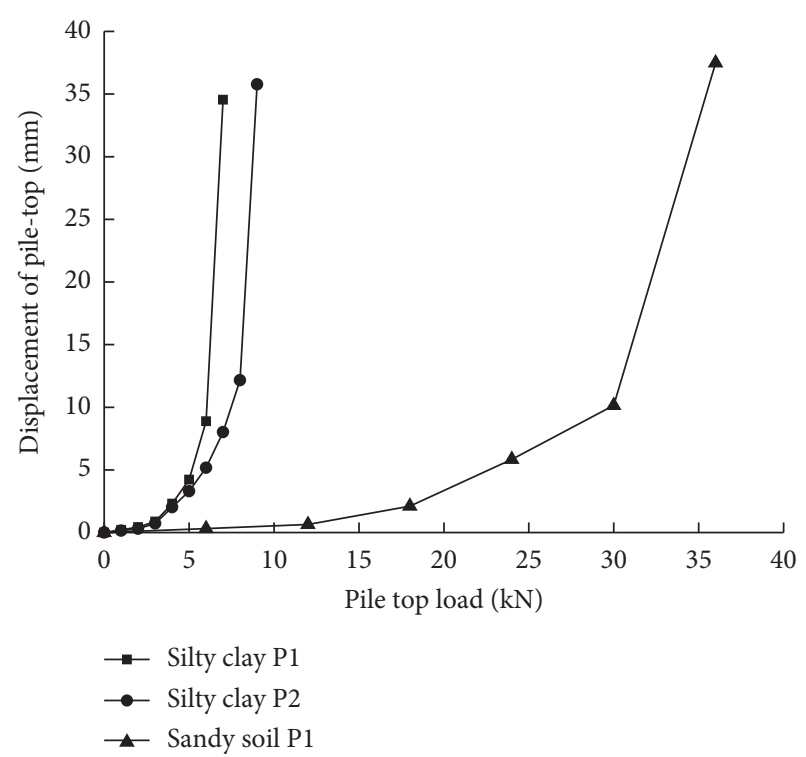

Figure 5: The tip displacement of pile in different soils along with load change.

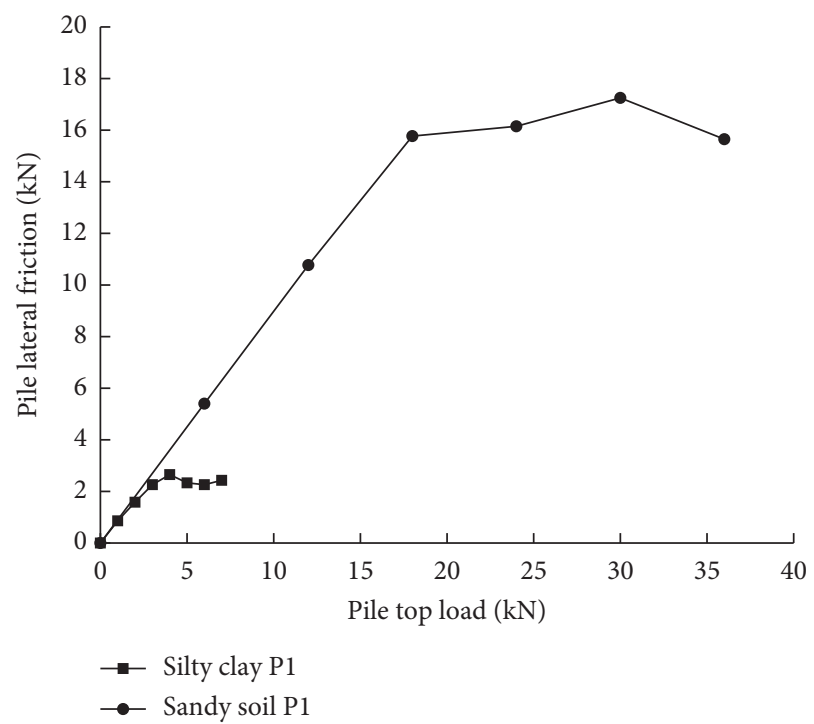

FIgURE 6: The lateral friction of pile in different soils along with load change.

Figure 7 illustrates the curves of lateral friction of single pile in different diameters along with load change. From that, we can see that the double-walled open-ended pile in 


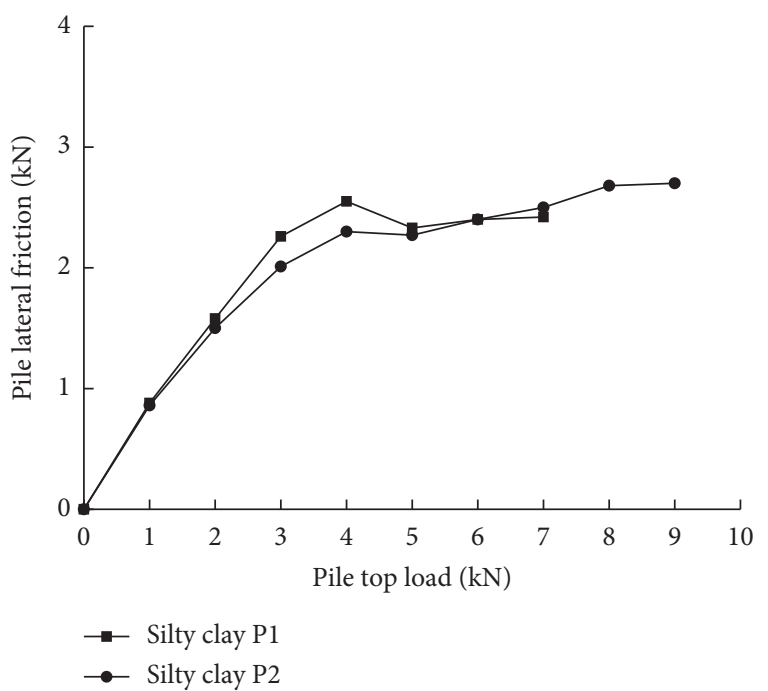

FIGURE 7: The lateral friction of pile with different diameters in soil samples along with load change.

the test has seen its lateral friction increased with the application of load at the tip increased at the same time. Applying the same load, the lateral friction of P1 is bigger than that of $\mathrm{P} 2$, or under the same load, the smaller the diameter of a pile, the larger the proportion of lateral friction.

Figure 8 shows the curves of tip resistance of single pile in different soils for different loading conditions. The curves show that the double-walled open-ended pile in the test has seen its tip resistance increased with the application of load at the tip increased at the same time. The increment speed of tip resistance in the silty clay is far faster than that in the sand. Applying the same load at pile tip, the tip resistance of pile in the silty clay is far bigger than that in the sand. The main reason is that the friction coefficient between the sand particles and the pile is larger than that in the clay, and the unit side friction resistance of the pile-soil interface in the sand can be exerted to a greater level than the clay. Under the same test conditions, the pile top load in sand needs to overcome the larger side friction resistance to be transmitted to the pile end, which results in a smaller increase in pile-end resistance in sand than in clay. Whether in sand or clay, the resistance at the end of the pile increases slowly at the beginning of the static load. With the application of the static load, the speed of the resistance at the end of the pile increases continuously until the increasing speed reaches stability. The main reason is that, with the load increases, the side friction resistance of the pile-soil interface gradually increases at the initial stage of static load, resulting in a relatively slow increase in pile-end resistance.

With the increase of the load, the side friction resistance of the pile body gradually reaches the maximum level. At this

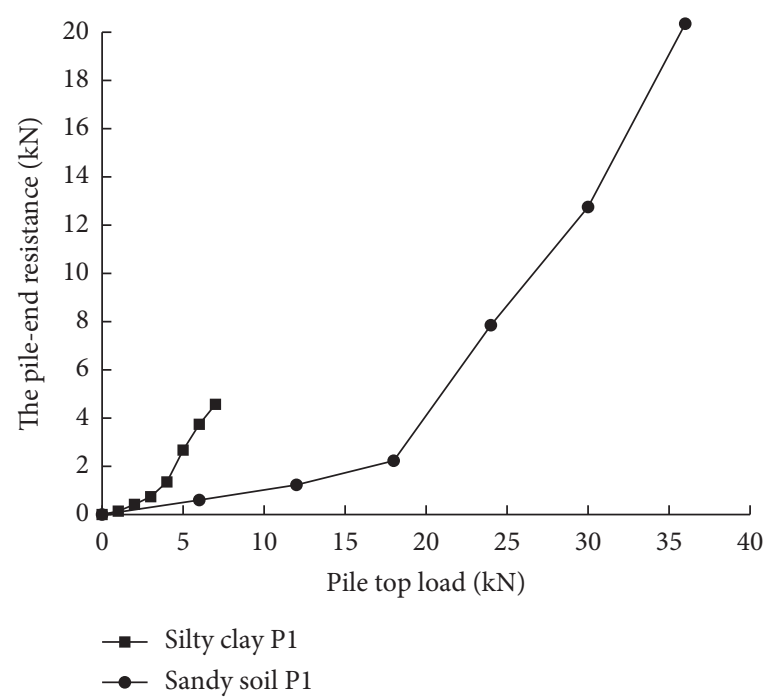

FIgURE 8: The tip resistance of pile in different soil samples along with load change.

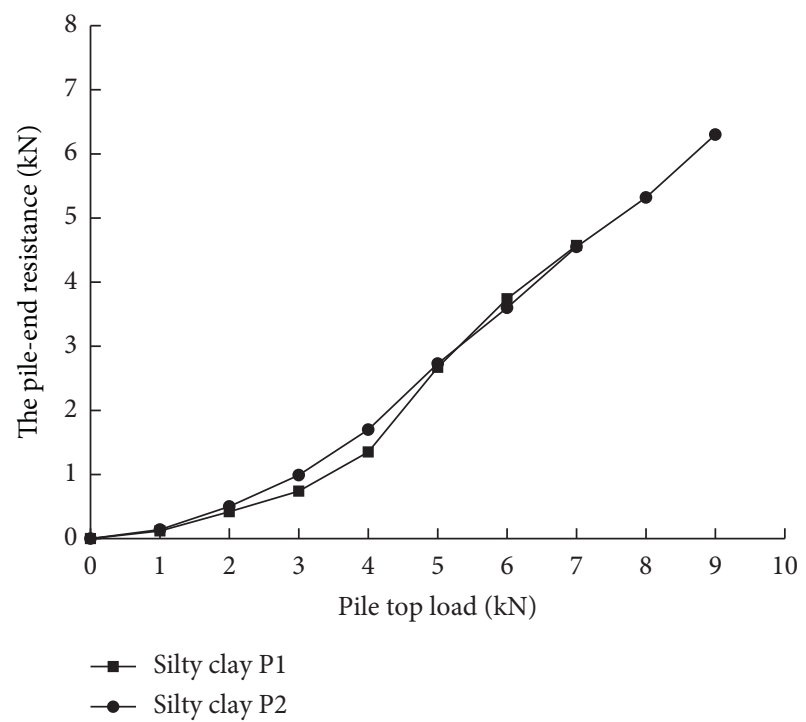

Figure 9: The tip resistance of piles with different diameters in various soil samples along with load change.

time, the load increases again, and the side friction resistance no longer increases, resulting in a larger increase in the pileend resistance.

The relationship between the tip resistance of the single pile and the pile load is revealed in the curved shown in Figure 9. From the figure, we can see that the double-walled open-ended pile in the test has its tip resistance increased slowly along with increase of load application at the pile tip. With further increase of load application at pile tip, the tip resistance starts to increase quickly. Under the same load, 
the tip resistance of $\mathrm{P} 2$ is bigger than that of $\mathrm{P} 1$, or under the same load, the bigger the diameter of a pile, the larger the proportion of tip resistance.

\section{Conclusions}

In this paper, we have studied the settlement mode of a single pile in the static load process, its bearing capacity and lateral friction, and the working properties of its tip resistance. Based on the results, the main conclusions can be drawn as follows.

(1) With increase of tip load, the vertical displacement of pile tip is increasing. Applying the same load at pile tip, the bigger the pile diameter, the smaller the settling volume. Under the same load, the settling volume of a pile in the sand is less than that in the silty clay.

(2) The bearing capacity of a pile in the sand is far bigger than that in the silty clay.

(3) Applying the same load at pile tip, the less the diameter of a pile, the larger the proportion of its lateral resistance, and the bigger the diameter of a pile, the larger the proportion of its tip resistance. With the increase of load application at pile tip, the tip resistance experiences slow to quick increase.

(4) Applying the same load at pile tip, the tip resistance of a pile in the sand is smaller than that in the silty clay. From that, we can see that, under the same load at pile tip, the lateral friction of a pile in the sand is bigger than that in the silty clay.

\section{Data Availability}

Some or all data that support the findings of this study are available from the corresponding author upon reasonable request.

\section{Conflicts of Interest}

The authors declare no conflicts of interest.

\section{Acknowledgments}

This research was funded by the National Natural Science Foundation of China (41772318).

\section{References}

[1] W. S. Gao, G. X. Mei, T. H. Zhou et al., "Innovation and development of foundation technology," China Civil Engineering Journal, vol. 53, no. 6, pp. 97-121, 2020.

[2] K. V. Terzaghi and R. B. Peck, Theoretical Soil Mechanics, John Wiley and Sons, New York, NY, USA, 1948.

[3] G. G. Meyerhof, "Compaction of sands and bearing capacity of piles," Journal of the Soil Mechanics and Foundations Division, vol. 85, no. 6, pp. 1-29, 1959.

[4] H. G. Poulos and N. S. Matters, "Settlement methods for pile groups and pile rafts," Aust. Géotechnique, vol. 47, no. 4, pp. 791-816, 1997.
[5] H. B. Seed and L. C. Reese, "The action of soft clay along friction piles," Transactions Proceedings, pp. 731-754, 1957.

[6] P. Wu, W. M. Gong, and S. T. Liang, "Study on load transfer law of overlength piles considering depth effect," Rock and Soil Mechanics, vol. 28, no. 12, pp. 1265-1268, 2007.

[7] S. M. He and G. S. Lu, "Study on load transfer characteristic of rock-socketed pole," Rock and Soil Mechanics, vol. 28, no. 12, pp. 2598-2602, 2007.

[8] C. S. Desai, "Numerical design-analysis for piles in sands," Journal of the Geotechnical Engineering Division, vol. 100, no. 6, pp. 613-635, 1974.

[9] H. G. Poulos and E. H. Davis, Pile Foundation Analysis and Design, John Wiley and Sons, New York, NY, USA, 1980.

[10] Y. Wang, X. Zhou, and X. Xu, "Numerical simulation of propagation and coalescence of flaws in rock materials under compressive loads using the extended non-ordinary statebased peridynamics," Engineering Fracture Mechanics, vol. 163, pp. 248-273, 2016.

[11] Y. Wang, X. Zhou, and Y. Shou, "The modeling of crack propagation and coalescence in rocks under uniaxial compression using the novel conjugated bond-based peridynamics," International Journal of Mechanical Sciences, vol. 128-129, pp. 614-643, 2017.

[12] Y. Wang, X. Zhou, Y. Wang, and Y. Shou, "A 3-D conjugated bond-pair-based peridynamic formulation for initiation and propagation of cracks in brittle solids," International Journal of Solids and Structures, vol. 134, pp. 89-115, 2018.

[13] Y.-T. Wang, X.-P. Zhou, and M.-M. Kou, “Three-dimensional numerical study on the failure characteristics of intermittent fissures under compressive-shear loads," Acta Geotechnica, vol. 14, no. 4, pp. 1161-1193, 2019.

[14] M. M. Kou, Y. J. Lian, and Y. T. Wang, "Numerical investigations on crack propagation and crack branching in brittle solids under dynamic loading using bond-particle model," Engineering Fracture Mechanics, vol. 212, pp. 41-56, 2019.

[15] M.-M. Kou, X.-R. Liu, Z.-Q. Wang, and S.-D. Tang, "Laboratory investigations on failure, energy and permeability evolution of fissured rock-like materials under seepage pressures," Engineering Fracture Mechanics, vol. 247, Article ID 107694, 2021.

[16] X. Hong and M. Yang, "A new calculation method for single pile load and settlement in layered soils," Chinese Journal of Underground Space and Engineering, vol. 3, pp. 431-435, 2008.

[17] Y. G. Wang, Z. R. Mei, and J. C. Zhang, "Experimental researches on bearing characteristics of a single pile," Chinese Journal of Geotechnical Engineering, vol. 32, no. 1, pp. 7-11, 2010.

[18] J. Zhou, J. J. Guo, Z. Zhang, and M. C. Jia, "Model test of single pile static load in sands and numerical simulation using particle flow code," Rock and Soil Mechanics, vol. 31, no. 6, pp. 1763-1768, 2010.

[19] Y. Diao, G. Zheng, J. Xu, H. M. Ouyang, and Y. Xu, "Comparative analysis of static uplift pile load tests under different loading conditions," Chinese Journal of Geotechnical Engineering, vol. 33, no. S2, pp. 464-470, 2011.

[20] X. Hong, "Theoretical simulation and factors for static loading tests on a single pile," Chinese Journal of Geotechnical Engineering, vol. 34, no. 1, pp. 176-183, 2012.

[21] Q. Gao, M. Y. Zhang, and X. Y. Bai, "Analysis of static load test of PHC piles in Jiaozhou Bay reclamation area," Engineering Construction, vol. 48, no. 1, pp. 58-78, 2016.

[22] K. Huang and M. Y. Zhang, "Analysis of static load test of rock-socketed driven piles in a certain area of Qingdao," Engineering Construction, vol. 49, no. 3, pp. 62-66, 2017. 
[23] S. L. Huo, H. Y. Deng, Q. Y. Yu, and M. X. Zhu, "Field test study on vertical bearing behavior of rock-socketed piles," Building Structure, vol. 50, no. S2, pp. 690-695, 2020.

[24] Technical Code for Building Pile Foundation (JGJ94-2008), Construction Science and Technology, 2012(Z1):38-39.JGJ9494. 